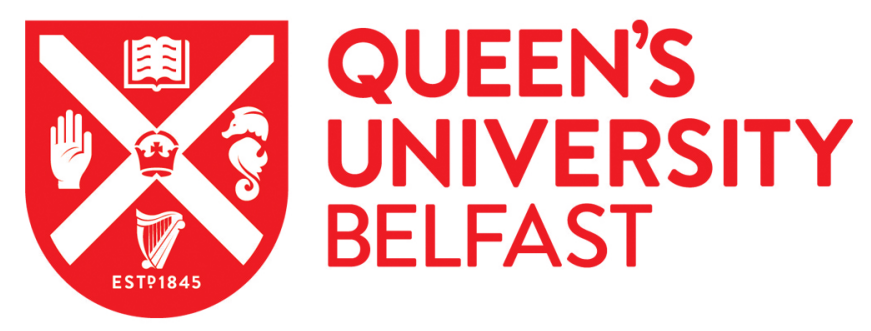

\title{
A Female Leadership Trust Advantage in Times of Crisis: Under What Conditions?
}

Post, C., Latu, I. M., \& Belkin, L. (2019). A Female Leadership Trust Advantage in Times of Crisis: Under What Conditions? Psychology of Women Quartlerly.

Published in:

Psychology of Women Quartlerly

Document Version:

Peer reviewed version

Queen's University Belfast - Research Portal:

Link to publication record in Queen's University Belfast Research Portal

Publisher rights

Copyright 2019 SAGE. This work is made available online in accordance with the publisher's policies. Please refer to any applicable terms of use of the publisher.

\section{General rights}

Copyright for the publications made accessible via the Queen's University Belfast Research Portal is retained by the author(s) and / or other copyright owners and it is a condition of accessing these publications that users recognise and abide by the legal requirements associated with these rights.

Take down policy

The Research Portal is Queen's institutional repository that provides access to Queen's research output. Every effort has been made to ensure that content in the Research Portal does not infringe any person's rights, or applicable UK laws. If you discover content in the Research Portal that you believe breaches copyright or violates any law, please contact openaccess@qub.ac.uk. 
A Female Leadership Trust Advantage in Times of Crisis: Under What Conditions?

Corinne Post

Lehigh University, USA

Ioana M. Latu

Queen's University Belfast, UK

Liuba Belkin

Lehigh University, USA

\section{Author Note}

Corinne Post, Department of Management, Lehigh University; Ioana M. Latu, School of Psychology, Queen's University Belfast, Belfast, UK; Liuba Belkin, Department of Management, Lehigh University.

We would like to thank Professors Michelle Ryan (University of Exeter) and Janaki Gooty (UNC Charlotte) for offering comments and suggestions that improved this work.

Correspondence concerning this article should be addressed to Ioana Latu, School of Psychology, Queen's University Belfast, Belfast, BT9 5BN, UK. E-mail: i.latu@qub.ac.uk 


\begin{abstract}
We examined differences in trust for men and women leaders who adopt relational behaviors during an organizational crisis. We addressed two important shortcomings of previous research. First, we independently manipulated leader gender and leader relational behaviors (interpersonal emotion management) to identify their separate and interacting influences on trust outcomes, which may lead to a leadership advantage for women. Second, we examined how uncertainty about crisis outcomes affects the strength of this advantage. We operationalized trust as both evaluative and behavioral (investment in a company led by the leader). We found support from two experiments $(N=412$ and $N=400)$ for the idea of a female leadership trust advantage in times of crisis. And we showed that the advantage is uniquely attributable to female leaders' use of relational behaviors and is manifested only when crisis consequences are known. We observed these effects both for evaluative trust (Studies 1 and 2) and behavioral trust (Study 2). We invite more research on the conditions that contribute to the female leadership advantage, the gendered nature of leadership behaviors during organizational crises, and the relational leadership qualities that help restore trust in organizations during uncertain times.
\end{abstract}

Keywords: leadership, trust, gender gap, contextual cues, organizational crises, online experiments 


\section{A Female Leadership Trust Advantage in Times of Crisis: Under What Conditions?}

Researchers have debated the potential advantage that women leaders bring to organizations in an extensive body of work (Eagly, 2016; Eagly, 2007; Eagly \& Carli, 2003). Because women are — on average — more likely than men to adopt a relational approach to leadership (Binns, 2008; Eagly, Johannesen-Schmidt, \& van Engen, 2003; Holmes \& Marra, 2004; Vongas \& Al Hajj, 2015), and because the relational requirements of work have increased (Grant, 2007), some argue that women may be more effective leaders than men (Grant, 1988; Rosener, 1990), an argument summarized as the "female leadership advantage" (Eagly \& Carli, 2003). The female leadership advantage argument suggests a potential advantage to female leaders during organizational crises. Relational skills can help build and restore trust and, thereby, enhance the effectiveness of crisis responses (Kahn, Barton, \& Fellows, 2013; Mishra, 1996). The relational approach to leadership originates in observations that some individuals tend to think of themselves in relation to others (Cunliffe \& Eriksen, 2011) and "leaders need to be sensitive, attuned, and responsive to moments of differences, and feel responsible for working with those differences" (Cunliffe \& Eriksen, 2011, p. 1438). Because, on average women (more so than men) conceive of themselves in interdependence with others and men (more than women) conceive of themselves as independent from others (Cross \& Madson, 1997; Howard, Gardner, \& Thompson, 2007), relational skills tend to be qualified as feminine rather than masculine.

Although the idea of a female leadership advantage is appealing, it stands on mixed empirical evidence (Eagly, 2016). Meta-analyzing 45 primary studies, Eagly and her colleagues (2003) show that while women adopt effective leadership behaviors (e.g., transformational leadership) somewhat more frequently than men, in practice men and women are almost equally 
likely to adopt a relational approach to leadership. Meta-analyzing 95 individual studies Paustian-Underdahl and colleagues' (2014) found that men and women enjoy similar ratings of leadership effectiveness. Ample evidence indicates that people dislike and punish women in nonconforming gender roles (Anderson, 2015; Rudman \& Glick, 2012). Despite real changes in, and favorable attitudes toward, women's access to male-dominated jobs, Haines and colleagues (Haines, Deaux \& Lofaro, 2016) find surprising stability in gender stereotypes. This may explain why, if a female leadership advantage exists, it has failed to help speed up the progress of women into top leadership roles, where they are still greatly under-represented (Catalyst, 2019).

Two important research limitations may contribute to the mixed empirical findings regarding a female leadership advantage. The first limitation is the use of leader gender as a proxy for relational behaviors or skills, thus confounding the effects of gender and relational skills in explaining the female leadership advantage. A second limitation is the inadequate attention to contextual factors, given that benefits derived from leaders' relational skills are likely to depend on the relational requirements of a given situation (Post, 2015); crisis characteristics shape expectations of leadership behavior (Cook \& Glass, 2014; Kulich, Iacoviello, \& Lorenzi-Cioldi, 2018; Kulich, Lorenzi-Cioldi, Iacoviello, Faniko, \& Ryan, 2015; Ryan, Haslam, Hersby, \& Bongiorno, 2011; Ryan et al., 2016). We focused on crisis resolution uncertainty in the current study to examine if crisis resolution requires relational skills.

In two studies, we evaluated the potential for a female leadership trust advantage, which would manifest as higher trustworthiness evaluations and trusting behaviors in response to women leaders compared with men leaders. We viewed trustworthiness as a perceived attribute, implying that the leader is viewed as worthy of being trusted (Chen, Saparito, \& Belkin, 2011; Mayer, Davis, \& Schoorman, 1995). And trusting behavior is the behavioral manifestation of 
trust in a leader (Berg, Dickhaut, \& McCabe, 1995; Huang \& Murnighan, 2010), which may manifest as investment in a company led by that leader (Flynn \& Staw, 2004).

In the current study, we theorized that interpersonal emotion management (IEM)-i.e., relational behaviors that anticipate and manage the emotions of others (Little, Gooty, \& Williams, 2016; Thiel, Griffith, \& Connelly, 2015; Williams, 2007)—would be a mechanism of the female leadership trust advantage argument; we evaluated when and how such an advantage emerges during an organizational crisis. By crisis, we mean a common, albeit often unexpected, time-sensitive, high-impact event that may disrupt organizational functioning and pose relational threats (Chopra \& Sodhi, 2004; Hendricks \& Singhal, 2008; Kahn et al., 2013; Pearson \& Clair, 1998). Examples include a product safety concern, a consumer data breach, an oil spill, a corruption allegation, or widespread harassment. Crises are fraught with relational issues, which, unless handled properly, threaten not only organizational performance, but also the allocation of organizational resources (Mishra, 1996) and even organizational survival (Weick, 1988, 1993; Weick \& Sutcliffe, 2001). Organizational crises, therefore, require a great deal of relational and emotional work to build or restore trust among those affected (Kahn et al., 2013) and may influence such trusting behaviors as the provision of resources to the organization (Mishra, 1996).

\section{A Female Leadership Advantage for Eliciting Trust in Organizational Crises?}

Because women are socialized to behave relationally and to embrace relational leadership (Buss, 1995; Eagly et al., 2003; Tooby \& Cosmides, 1990; Trivers, 1972; Vongas \& Al Hajj, 2015; Wood \& Eagly, 2002) and because of the relational requirements that define crisis resolution (Mishra, 1996), we evaluated, in the current studies, whether and when female leaders may have an advantage (over male leaders) in eliciting trust during organizational crises. Here, 
we elaborate on two important qualifiers to the emergence of such a potential female leadership trust advantage: (a) female leaders must exhibit relational behaviors and (b) the situation must require relational skills.

A central premise of the so-called female leadership advantage argument is that relational behaviors foster trust. Yet, relational leadership practices often are invisible (Dutton \& Dukerich, 2006), seldom recognized, and quite difficult to measure (Fletcher, 1998; Williams, 2007). Perhaps because of these limitations, researchers who study gender differences in relational leadership rarely assess the influence of specific relational behaviors but instead, adopt essentialist assumptions about women and men's behaviors, which fail to accurately reflect how men and women actually behave (Hyde, 2005; Hyde, Bigler, Joel, Tate, \& van Anders, 2018. Drawing on recent developments in this area, namely in the area of interpersonal emotion management (IEM; Little et al., 2016; Thiel et al., 2015; Williams, 2007), we investigated the importance of situationally appropriate relational behaviors.

Interpersonal emotion management (IEM) refers to threat-reducing behaviors that anticipate and manage the emotions of others. IEM are relational behaviors, because they refer to "the process of influencing the internal feeling state(s) of another person" (Niven, Totterdell, \& Holman, 2009, p. 498), are undertaken for the benefit of others, and require sensitivity to and care for others. IEM behaviors include situation modification ("removing or altering a problem to reduce emotional impact"), attentional deployment (“directing the target's attention to something more pleasant"), cognitive change ("reappraising a situation as more positive"), and modulating one's emotional response (“suppressing emotional responses”; Little, Kluemper, Nelson, \& Gooty, 2012, p. 408), all in anticipation of, and with the intent to manage, the emotions of others. We selected IEM as the focal relational leadership behavior because IEM is: 
(1) central to trust establishment or repair, which crises often erode (Chopra \& Sodhi, 2004;

Hendricks \& Singhal, 2008; Kahn et al., 2013; Pearson \& Clair, 1998) and (2) is intersubjective and behavioral (Williams, 2007).

Moreover, empirical evidence suggests that IEM is distinct from other related concepts, such as emotional intelligence (Little et al., 2012) or psychometric intelligence (Mayer, Caruso, \& Salovey, 2000; Salovey \& Mayer, 1989), as the IEM construct captures specific behaviors, rather than traits and abilities. IEM is also distinct from intrapersonal emotion regulation (Côté \& Hideg, 2011), since IEM is concerned with the interpersonal emotion management and differs from perspective taking, empathic concern, emotion regulation of the self, and emotional intelligence (Little et al., 2012; Niven, Holman, \& Totterdell, 2012). IEM is specifically concerned with the anticipation and management of others' threat perceptions.

Consider the following business case example: IBM's 2004 announcement of the purchase of its PC business by the Chinese firm Lenovo was a time-sensitive, high-impact event, with the potential to disrupt IBMs' functioning and relationships within the company. For Janet Ang, then vice-president for IBM's PC business in China, and her team, it was completely unexpected. She described managing the high uncertainty that came with this announcement by refocusing her team towards aspects of the situation that they may find more appealing. As Janet Ang recalled it, in communicating the shocking news to her team, she "painted a vision of us creating history. Taking a Chinese company truly global and being part of that history in the making such that years down the road we can all be telling our grandchildren we made it." In addition, by sharing "with them that it is okay to feel mad, to feel betrayed. We'll just have to work through it. We have the weeks ahead to work through it" she put the problem into perspective for her team. Ang credited this IEM approach for the success of the acquisition 
(Feland, 2008).

The relational requirements of the situation (crisis) should alter the extent to which female leaders, if they are more relational, accrue a trust advantage through their relational behavior (Post, 2015). The think crisis-think female stereotype (Ryan et al., 2011) applies when evaluators believe the crisis requires managing people, taking responsibility for the crisis, or enduring it; and perceive women as better at managing people, taking the blame for crises, and soldiering through them (Ryan et al., 2011); but not when evaluators perceive the crisis to require a task-orientation or a corporate turnaround strategy (Kulich et al., 2018). We examined how uncertainty surrounding a crisis further qualifies the female leadership trust advantage. Specifically, in two experimental studies, we investigated how the use of IEM shapes the emergence of a female leadership advantage for incumbent leaders during an organizational crisis. We distinguished between crises that have predictable versus unpredictable outcomes. In doing so, we attempt to refine the conditions under which a female leadership trust advantage occurs.

\section{Leaders' Interpersonal Emotional Management Behaviors Foster Trust in Crises}

We theorized that leaders who use IEM strategies (i.e., high-IEM leaders) when addressing organizational crises, compared to leaders who do not (i.e., low-IEM leaders), will: (a) receive higher evaluations of relationally trustworthy (relational resources) and (b) elicit more investments (economic resources), for two main reasons. First, a leader's threat-reducing behavior (i.e., IEM) leads others, whether they are subordinates or colleagues, to experience more affective attachment to the threat regulator (i.e., the leader) and, therefore, to evaluate them as being more trustworthy (Williams, 2007). Affect theory of social exchange (Lawler, 2001) explains that dyadic social exchanges that induce positive feelings (e.g., threat reduction, relief) 
in a social exchange partner (e.g., follower) enhance the partner's positive feelings (e.g., trust) toward the other social exchange partner (e.g., leader), because the positive feeling is attributed to the other exchange partner. Second, IEM is a social process that conveys information to the recipient about the sender's intentions and abilities. IEM is likely to signal a leader's benevolence - one of the key aspects of trustworthiness (Belkin \& Rothman, 2017) and a central precursor of trust (Mayer et al., 1995)—because IEM helps reduce the recipient's "fears associated with the potential for opportunism, neglect, and identity damage and [...] may be perceived as [a] benevolent, emotionally supportive" action (Williams, 2007, p. 611).

A leader's use of IEM strategies also provides information about the leader's ability to manage and resolve the crisis at hand and, thus, may elicit trust (Mayer et al., 1995). Because crises are negative affective events fraught with relational disturbances (Kahn et al., 2013), high IEM should signal a strong potential for positive crisis resolution and, therefore, mitigate a loss of confidence by stakeholders. High IEM, relative to low IEM, is likely to increase a leader's trustworthiness by regulating the perceived threat that a negative affective event, such as a production or a consumer safety crisis, may pose to others. In the absence of other information about a leader's intentions and behaviors, IEM may diminish concerns related to the potentially opportunistic behaviors of people in positions of authority (Lind, 2001).

We expected that leaders with high IEM garner more relational resources (e.g., employee trust and cooperation), as well as economic resources (e.g., investments into their firms) relative to low-IEM leaders. Leaders who demonstrate empathy and affective concern for others help teams with high relational requirements to function more effectively (Kirkman, Li, \& Porter, 2014; Post, 2015). Leaders who employ perspective taking, one aspect of IEM, foster more cooperation and collaboration (Williams, Parker, \& Turner, 2007). And, because leaders are 
generally expected to be competent in managing their and others' emotions (Humphrey, 2002), leaders who display superior emotion management abilities may not only establish better interpersonal relationships (Gross \& John, 2003; Salovey \& Mayer, 1989), but also strengthen others' beliefs in the leader's ability to manage crises. We hypothesized that, in crises, leaders who used IEM strategies (as compared to leaders who do not) would be evaluated as more trustworthy and would elicit more economic resources (e.g., investments).

We also hypothesized that female leaders who use high IEM would be likely to elicit even more trust (compared to male leaders using similarly high IEM); high IEM is more gendercongruent with stereotypes about women than it is with stereotypes about men, and role congruity elicits more favorable evaluations (Eagly, Karau, \& Makhijani, 1995). The congruity of leaders' behaviors with leader role expectations and gender role expectations may influence evaluations of those leaders, rendering those who violate gender norms less likeable (Rudman \& Glick, 1999, 2001). Gloor and her colleagues showed that when team members reported that their "leader is a typical leader, exhibits the behavior of a leader, and fits one's image of a leader" they also elicit more trustworthiness (Gloor, Morf, Paustian-Underdahl, \& BackesGellner, in press, p. 14). In crises, we expected the emergence of a female leadership trust advantage to be contingent on leaders' performance of IEM behaviors, because of crises' relational requirements (Kahn et al., 2013; Mishra, 1996), That is, we hypothesized that female leaders elicit more trust than male leaders when they use high-IEM behaviors.

We also hypothesized that the leadership trust advantage women enjoy when they use high IEM would be larger when firms face a less uncertain, more controllable crisis. When there is more certainty about the crisis resolution path and the fallout from the crisis is more controllable, crisis management may benefit from leadership that focuses primarily on relational 
aspects within the organization (e.g., Slatter, Lovett, \& Barlow, 2011; Wooten \& James, 2008). Researchers have shown that leaders' relational abilities (e.g., the ability to manage people and personnel issues) are perceived as more useful in performance crises over which leaders have more control (Ryan et al., 2011). In contrast, crises that are difficult to control may require agentic leadership, because dealing with such uncertainty and uncontrollability requires not just managing people's emotions, but also taking decisive action to change the course of unfolding events. In a study evaluating leadership expectations, for example, participants confronted with a high-uncertainty crisis reported wanting leaders to be both agentic (e.g., making decisions and acting quickly) and relational (e.g., maintaining very high levels of communication; Haddon, Loughlin, \& McNally, 2015). Thus, we expected the female leadership trust advantage to be larger for female leaders who exhibit high IEM in more controllable crises, when the need for agentic skills is not salient.

\section{The Current Study}

We designed two experimental studies that manipulated leader gender, IEM behaviors, and types of crisis uncertainty and trust both through self-reports of evaluative trust (e.g., the assessment of the leader's likelihood of taking advantage of the assessor) and through a behavioral (investment) measure. The overall hypothesis for the current studies was that the female leadership trust advantage would depend on the use of relational behaviors and the situational characteristics of the crisis. We tested if (Hypothesis 1) hypothetical leaders with high-IEM behaviors would elicit more evaluative and behavioral trust compared to those with low-IEM behaviors. We predicted that (Hypothesis 2) female leaders (more than male leaders) would elicit more evaluative and behavioral trust when they use high-IEM behavior. And we examined (Hypothesis 3) whether or not the leadership trust advantage for women who use high 
IEM would emerge when a firm faces a less (as opposed to more) uncertain crisis.

\section{Study 1}

\section{Method}

Participants. We recruited 476 participants from Amazon Mechanical Turk (MTurk). Participants completed our experiment online in exchange for a payment of $\$ 1.01$ (Berinsky, Huber, \& Lenz, 2012). Mturk samples have been used successfully across multiple studies in organizational, psychological, and economics research, among others (Gosling, Vazire, Srivastava, \& John, 2004; Horton, Rand, \& Zeckhauser, 2011; Landers \& Behrend, 2015). Often, MTurk samples are more diverse than other samples such as face-to-face or social media and produce data of adequate quality (Buhrmester, Kwang, \& Gosling, 2011; Casler, Bickel, Hackett, 2013). To control for MTurk response quality, we excluded 64 responses with non-unique MTurk ID or computer IP address, or that failed to pass our attention check questions; the final sample consisted of 412 participants. Ages ranged from 21 to 29 years $(34.4 \% ; n=142)$ to over 60 years old $(3.9 \% ; n=16)$, with the most common categories being $30-39(38.3 \% ; n=158)$. Forty-eight percent identified themselves as male $(n=200), 34.4 \%(n=142)$ had some college education, $39.2 \%(n=162)$ graduated from college, $12.3 \%(n=51)$ completed graduate school, 97.3\% $(n=402)$ were native English speakers.

Design and procedure. We randomly assigned participants to a 2 (Situational Uncertainty: low vs. high) x 2 (Leader IEM: low vs. high) x 2 (Leader Gender: male vs. female) between-subjects design. In order to manipulate the variables, we used short written vignettes about an aeronautics company during a time of crisis. We adapted our scenario from a vignette (E. Fragnière, personal communication, December 12, 2011) that dramatizes typical crises arising between the production and R\&D functions, as documented in a study of human risks in 
Swiss watch manufacturing and British aerospace manufacturing (Jolivet, 2013). The scenario describes a firm's significant investment of time and energy in R\&D and knowledge development that led to the design of a new product that the firm intends to produce for largescale commercialization. The firm's production team has prepared and fine-tuned the production lines according to specifications from the design team. The firm received government certification for the product, thus enabling production to begin. However, shortly after production begins, a technician discovers a major product flaw and immediately alerts his supervisor, the production team leader. The unforeseen production problem constitutes the organizational crisis in our experiment.

After participants read and agreed to the informed consent, we randomly assigned them to read one of the eight vignettes (see Supplementary File Section A at http...). After reading the scenario, to ensure the quality of the sample, participants answered three attention check questions (i.e., "What is the name of the Production Team manager in the description above?" "What is the name of the Design Team manager in the description above?" and "What is the problem in the case described above?"), followed by the manipulation check questions and dependent measures, after which we thanked the participants and provided the code that they can submit for the study payment.

Manipulations. We manipulated the IEM behaviors of the production team leader with different descriptions of their interactions with another leader. To construct the manipulations, we used Little and colleagues' (2012) four categories from the IEM Scale. In the high-IEM condition, participants read that the production leader (i) takes a deep breath to calm down before contacting the target/subordinate (emotional response suppression); (ii) diffuses some of the emotional weight of the situation by requesting a meeting with the target/subordinate in 30 
minutes in a location removed from the factory floor (situation modification); (iii) starts the meeting by putting the target/subordinate at ease and putting the problem into perspective (cognitive change); and (iv) does not assign blame to the target/subordinate, but rather calls attention to the task ahead (attentional deployment).

In the low-IEM condition, participants read that the production leader (i) makes no attempt to calm down before contacting the target (no emotional response suppression); (ii) requests an immediate meeting with the target in the location where the problem occurred (no situation modification); (iii) starts the meeting without letting the target say a word, heatedly describes in details how the problem was discovered, and provides a negative interpretation of the situation (no cognitive change); and (iv) focuses on the negative aspects of the situation (no attentional deployment). We distinguished men and women by manipulating the production leader's name: David in the male leader scenario and Heather in the female leader scenario.

We differentiated high and low uncertainty crises by manipulating the level of uncertainty in the causes and potential resolution paths of the crisis. We devised the uncertainty manipulations using Szulanski, Capetta, and Jensen's (2004) causal ambiguity scale. In the highuncertainty condition, participants read that (i) there is no available information to identify the precise reason for the production problem, (ii) the leader evaluated that it was nearly impossible to determine the precise reason for the problem, and (iii) no manuals and operation procedures were available for resolving the problem. In the low-uncertainty condition, participants read that (i) the leader quickly determined the origin of the problem, (ii) the leader determined that "they" could explain the precise reason for the problem, and (iii) manuals and operation procedures were available for resolving the problem.

Measures. To check the effectiveness of the IEM manipulations, we adapted six items 
from Little and colleagues' (2012) scale, with items such as “changes aspects of the situation to alter the crisis' emotional impact," "avoids negative emotions by putting the problem into perspective," and "refocuses the conversation towards aspects of the situation that the other manager may find more appealing." Response options ranged from $1=$ strongly disagree to $7=$ strongly agree. A factor analysis indicated that all six items loaded onto one factor (Eigenvalue $=$ 4.70, explaining $78.26 \%$ of the variance in the model, individual factor loadings available in Table 1, Supplementary File Section B at http...) and we thus averaged them into one measure of IEM (Cronbach's $\alpha=.94)$, where higher scores indicate high IEM.

To check the effectiveness of the uncertainty manipulations, we adapted four items from Szulanski and colleagues' (2004) scale. These items measured the extent to which participants perceived the problem to have a clear cause ("The people involved know what caused the problem") and also the extent to which there were available procedures to resolve the problem ("Manuals and operating procedures are available for resolving the problem"). Respondents rated the items on a 7 -point Likert scale $(1=$ strongly disagree to $7=$ strongly agree $)$. We averaged the items into an overall uncertainty score (Cronbach's $\alpha=.94$, Eigenvalue $=3.03$, explaining $75.77 \%$ of the variance in the model, individual factor loadings available in Table 2 , Supplementary File Section B at http...), with higher numbers denoting less uncertainty regarding the cause and resolution of the problem.

We measured evaluative trust along the dimensions of benevolence and integrity (Mayer et al., 1995), as they best capture the relational aspect of trustworthiness. We used the items from Mayer and Davis' (1999) benevolence-integrity scale and elicited responses, example items including: "the production manager will be very concerned about my welfare," and "the production manager seems to try hard to be fair in dealings with others." Response options 
ranged from $1=$ strongly disagree to $7=$ strongly agree. The 11 items loaded onto a single factor (Eigenvalue $=8.60$, explaining $78.20 \%$ of the variance in the model, individual factor loadings available in Table 3 in Supplementary File Section B at http...), so we combined them into one scale (Cronbach's $\alpha=.97)$. The scale was also validated in previous research (Mayer \& Davis, 1999), in a sample of employees at a US manufacturing firm over a period of 14 months in a three wave design (Wave 1: $N=155$, Wave 2: $N=170$, and Wave 3: $N=193$ ), with $\alpha$ coefficients ranging from .82 to .89 .

\section{Results}

Manipulation checks. We first investigated the success of our IEM manipulation by conducting a 2 (Situational Uncertainty: low vs. high) x 2 (Leader IEM: low vs. high) x 2 (Leader Gender: male vs. female) between-subjects ANOVA on the average IEM manipulation check score. We found support for the predicted main effect of IEM condition, $F(1,407)=$ $1183.27, p<.001$, partial $\eta 2=.74$, such that respondents in the high-IEM condition reported that the leader exhibited higher IEM $(M=5.72, S D=.90)$ as compared to respondents in the low-IEM condition $(M=2.54, S D=0.97)$. This finding indicates that we successfully manipulated IEM.

We next investigated whether we were successful in manipulating uncertainty by conducting a 2 (Situational Uncertainty: low vs. high) x 2 (Leader IEM: low vs. high) x 2 (Leader Gender: male vs. female) between-subjects ANOVA on the average uncertainty manipulation check score. We found support for the predicted main effect of uncertainty condition, $F(1,407)=164.39, p<.001$, partial $\eta 2=.29$, indicating that respondents in the "high-uncertainty" condition reported that the problem had less certain causes and resolution paths $(M=4.65, S D=1.90)$ than respondents in the "low-uncertainty" condition reported $(M=$ 
$5.89, S D=0.86)$. This finding suggests that we successfully manipulated uncertainty.

Main analyses. We investigated the overall hypothesis that the female leadership advantage depends concomitantly on the use of relational behaviors and situational characteristics of the crisis by conducting a 2 (Situational Uncertainty: low vs. high) x 2 (Leader IEM: low vs. high) x 2 (Leader Gender: male vs. female) between-subjects ANOVA on the average Trust score. As predicted by our Hypothesis 1, results showed a main effect of Leader IEM, $F(1,405)=950.08, p<.001$, partial $\eta 2=.70$, such that participants trusted more the leader who displayed high-IEM behaviors $(M=5.73, S D=0.88)$ compared to low-IEM behaviors $(M=$ $2.79, S D=1.05)$ in response to a crisis.

Supporting Hypothesis 2, an interaction between IEM and leader gender $F(1,405)=$ $5.05, p=.02$, partial $\eta 2=.012$ qualified these main effects. Figure 1 displays this interaction. Planned contrasts showed that participants trusted female leaders high in IEM $(M=5.94, S D=$ $0.77)$ more than female leaders low in IEM $(M=2.78, S D=1.00), t=23.63, p<.0001$, Cohen's $d=3.54$. Moreover, respondents trusted female leaders high in IEM $(M=5.94, S D=0.77)$ more than male leaders high in IEM $(M=5.52, S D=0.95), t=3.05, p=.002$, Cohen's $d=0.49$, thus showing a female leadership advantage for women who use relational behaviors when facing a crisis. However, this advantage was not present for women who do not use relational behaviors. There was no difference in trust levels for female leaders low in IEM $(M=2.78, S D=1.00)$ compared to male leaders low in IEM $(M=2.81, S D=1.11), t=0.20, p=.84$, Cohen's $d=0.03$. We note that an ANOVA with participant gender included as a fourth factor showed that participant gender did not further moderate this interaction, $F(1,396)=0.72, p=.79$.

The uncertainty condition had no main effect on trust, $F(1,405)=0.95, p=.33$, partial $\eta 2=.002$, and did not interact with any of the other variables $\left(F_{\mathbf{s}}<1\right)$. The predicted three-way 
interaction between all factors was not significant, $F(1,405)=0.67, p=.41$, partial $\eta 2=.002$. Thus, our Study 1 data do not support Hypothesis 3.

\section{Discussion}

Our first goal with Study 1 was to test the conditions under which a female leadership trust advantage occurs in times of organizational crisis for incumbent leaders. We showed that high-IEM leaders elicited more trust than low-IEM leaders. We also showed that female leaders enjoy a trust advantage (compared to males) only when they displayed highly relational (highIEM) behaviors. The results did not support the hypothesis that the leadership trust advantage for high-IEM women only occurs under situations of low uncertainty. One explanation for the lack of effect may be in the way that we conceptualized uncertainty, which referred to ambiguity regarding the cause and resolution of the crisis, rather than uncertainty pertaining to its consequences. Whether the cause of the crisis is known or not (causal ambiguity) may not influence trust evaluations, regardless of how the leader is approaching the crisis. Crisis uncertainty may be more influential to the extent that it refers to whether the consequences of the crisis are perceived to be more or less certain (controllable). A defining characteristic of uncertainty is "the sense of doubt about future events or about cause and effect relationships in the environment" (Bordia, Hobman, Jones, Gallois, \& Callan, 2004, p. 508). Thus, we conducted a second study to test this hypothesis and replicate the findings of Study 1, while extending the trust advantage to include a behavioral measure of trust.

\section{Study 2}

In Study 1 we found support for the hypothesis that a female leadership trust advantage only occurs for women high in IEM. We conducted a second study to replicate and extend this effect in three critical ways. First, as mentioned above, we modified the uncertainty manipulation 
to convey lack of certainty about the consequences rather than cause of the crisis. In doing so, we followed Milliken's (1987) conception of effect uncertainty and defined it in Study 2 as crisis characteristics that elicit a generalized perception of unpredictability or doubt regarding how the crisis may affect the organization's future. The modified uncertainty manipulation suggested that even if managed properly, the crisis has either unknown effects (high uncertainty) or no negative effects (low uncertainty) on the sales of the company long-term. All Study 2 vignettes described the cause of the crisis as equally uncertain to avoid respondents' attribution of the crisis to the leader's competence.

Second, we wanted to replicate findings from Study 1 in a gender-neutral domain. In Study 1 , the crisis vignette occurred in the production team of an aeronautics company, a typically masculine industry. This male gender typicality may bias participants' perception of female leaders and may also skew perceptions regarding the importance of relational behaviors (Garcia-Retamero \& Lopez-Zafra, 2006). In Study 2 we used a more gender-neutral domain, the fast food industry, in which a crisis occurred when one of the company's products led to an outbreak of food intoxication (See Supplementary File Section A at http.....).

Third, we used a behavioral measure of trust to mitigate the social desirability concerns and to mitigate the weaknesses of self-report trust measures. We modeled the behavioral measure of trust after investment games that behavioral economists often use to measure individuals' trust in their interaction partner (Berg et al., 1995; Glaeser, Laibson, Scheinkman, \& Soutter, 2000). In the original version of these games, trust is assessed by measuring the amount of money Partner A sends to a Partner B, knowing that Partner B may or may not return part of the sum sent by Partner A. We adapted this game to measure trust in a leader, by giving participants a sum of money that they have the opportunity to invest either in the company in crisis, or in a 
similar company that is not in crisis. If participants trusted the leader's ability to successfully manage the company out of a crisis, we expected higher amounts would be invested in the target company relative to other similar companies.

\section{Method}

Participants and design. We collected data from 400 participants, in exchange for a payment of \$1.01 (Berinsky, Huber, \& Lenz, 2012), online through Mechanical Turk (MTurk). We restricted participation to U.S. residents and master workers, who have demonstrated accuracy on specific types of HITs on the Mechanical Turk marketplace, resulting in a sample of 398 usable participants. Our sample was balanced in terms of gender, with 189 men $(47.3 \%)$ and 209 women $(52.3 \%)$. In terms of education, 3 participants had some high school education, 41 participants (10.3\%) had a high school diploma, 78 had some college education (19.5\%), 59 an Associate Degree (14.8\%), 171 a Bachelor's degree (42.8\%), and 45 had a graduate degree (11.3\%). In terms of employment status, although we specified that only individuals employed full or part time should participate, we had 26 participants $(6.6 \%)$ who did not describe themselves as being employed. Otherwise, 308 (77\%) of participants were employed full-time and $64(16 \%)$ were employed part-time.

Materials. The manipulations and materials (provided in the Supplementary File) were identical with those we used in Study 1, with the three following exceptions. We modified the experimental scenarios to describe a crisis that took place in the fast-food industry. The vignette described a crisis involving twelve people becoming ill after eating a popular item on the menu of QuickMEX, a Mexican fast food company. The company had to deal with customer calls, media interview requests, and calls from the Food and Drug Administration officials. In this crisis, the IEM measures (high and low) remained the same as those described in Study 1 with 
one exception: for the vignette to reflect only externally visible leader behaviors, we removed the emotion suppression item, which describes an internal state of the leader.

We adapted the manipulation of uncertainty to suggest high or low uncertainty and potential for control of the long-term consequences of the crisis. In the low uncertainty condition the leader stated "At least if we act fast now, these crises are not likely to affect the long-term sales of the company. According to industry experts, customers are usually loyal and appreciate a company's efforts to find solutions." In the high uncertainty condition, the leader stated: “Unfortunately, even if we act fast now, we don't know how this crisis will affect the long term sales of the company. According to industry experts, one cannot anticipate whether customers are loyal and appreciate a company's efforts to find solutions to such a crisis." We used five items to check the success of our uncertainty manipulation: respondents rated the items: "It is unclear how the crisis will affect QUICK MEX Inc's sales in the future," "Currently, QUICK MEX Inc is facing an uncertain future," and "It is difficult to know how QUICK MEX Inc will fare after the current crisis" on a scale from $1=$ strongly disagree to $7=$ strongly agree and rated the items "How predictable are future sales at QUICK MEX?," and "How predictable is customer loyalty at QUICK MEX?” on a scale from $1=$ always predictable to 7 = never predictable. We averaged them into one overall perceived uncertainty score $(\alpha=.89$, (Eigenvalue $=3.45$, explaining $68.97 \%$ of the variance in the model, individual factor loadings available in Table 4 in Supplementary File Section B at http...), with higher numbers denoting more perceived uncertainty of the crisis.

Behavioral trust (investment). Besides the self-reported trust measure used in Study 1 (Cronbach's $\alpha=.96$ for Study 2 participants), we introduced a behavioral measure of trust (Berg et al., 1995; Glaeser et al., 2000). We asked participants to imagine that they are given the sum 
of $\$ 500$ and are required to invest the entire sum by buying shares of fast food companies. We told them that two companies currently accept investments: the target company, QuickMEX, and a similar fast food company (we gave relevant data about history and sales of the companies, while still ensuring they were similar overall). We informed participants that they could invest the entire sum in one of the two companies, or divide their $\$ 500$ investment between the two companies. To obtain the measure of trust, we computed the difference score between investment in QuickMEX and in the other company. The difference score can range from -500 to 500, with higher positive numbers suggesting more likelihood of investing (i.e., behavioral trust) in QuickMEX and a score of zero would suggest equal investment in both companies (i.e., equal trust).

\section{Results}

Manipulation check. We first conducted our manipulation checks for the revised uncertainty manipulation using a univariate ANOVA, comparing mean uncertainty scores between the low and high situational uncertainty conditions. Results showed a significant effect of uncertainty condition, $F(1,397)=26.59, p=.0001$, partial $\eta 2=.06$; participants perceived that the effects of the crisis on the future of the company were more uncertain in the highuncertainty condition $(M=5.38, S D=1.08)$ compared to the low-uncertainty condition $(M=$ $4.83, S D=1.11)$. Thus, our manipulation of uncertainty was successful.

Effects on behavioral trust (investment). We next investigated our overall hypothesis, according to which people's willingness to invest in a company in crisis depends on leader gender, leader behavior, and situational uncertainty. We conducted a 2 (Situational Uncertainty: low vs. high) x 2 (Leader IEM: low vs. high) x 2 (Leader Gender: male vs. female) betweensubjects ANOVA on the investment difference score. We note that we also conducted an 
alternative mixed 2 (Investment: QuickMEX vs. other company) x 2 (Situational Uncertainty: low vs. high) x 2 (Leader IEM: low vs. high) x 2 (Leader Gender: male vs. female) ANOVA with repeated measures on the first factor. This analysis showed a similar pattern, with the predicted 4-way interaction, $F(1,392)=7.72, p=.006$. However, for ease of graphing and interpretation, we present the analysis on the investment difference score below.

Supporting Hypothesis 1, results showed a main effect of Leader IEM, $F(1,392)=6.49$, $p=.01$, partial $\eta 2=.016$, such that participants were more likely to invest in QuickMEX relative to another company when the leader displayed high-IEM behaviors $(M=-11.81, S D=300.37)$ compared to low-IEM behaviors $(M=-88.60, S D=290.00)$ in response to a crisis. Lending support to Hypothesis 3, the predicted 3-way interaction, $F(1,392)=7.72, p=.006$, partial $\eta 2=$ $.019^{3}$, qualified the main effect of IEM. We note that an ANOVA with participant gender included as a fourth factor showed that participant gender did not further moderated this key interaction, $F(1,382)=0.03, p=.86$. Figure 2 visually represents the 3 -way interaction.

We also conducted planned contrasts to probe this interaction. We first analyzed differences in investment by gender and leader IEM when the crisis was characterized by low uncertainty. Consistent with Hypothesis 2, participants tended to invest in the company led by a woman high in IEM $(M=55.00, S D=288.14)$ more than in the company led by a man high in $\operatorname{IEM}(M=-40.42, S D=310.27), t=1.65, p=.09$, Cohen's $d=0.32$. However, this female leadership advantage was not present for leaders low in IEM, $t=0.94, p=.35$, Cohen's $d=0.20$, with participants being as unlikely to invest in a company led by a woman low in IEM $(M=$ $110.16, S D=301.57)$ as in a company led by a man low in $\operatorname{IEM}(M=-54.17, S D=260.90)$. Furthermore, participants were more likely to invest in a company led by a woman showing high IEM compared to a company led by a woman showing low IEM, $t=2.90, p=$ 
$.004, d=0.56$. For men, there was no difference between investment for high- and low-IEM leaders $(M=-54.17, S D=260.90), t=0.23, p=.82$, Cohen's $d=0.05$. However, these withingender comparisons were not critical to demonstrating a female leadership advantage. Nevertheless, we these overall findings show that the only positive difference score - that participants are more likely to invest in QuickMEX during crisis compared to another company-occurred when a woman displaying high-IEM behaviors led the company, during a low-uncertainty crisis.

We then analyzed differences in investment by gender and leader IEM under conditions of high uncertainty. When a company's future was highly uncertain and the leader was a woman, there was no difference in investment between a company led by a low-IEM leader $(M=-41.25$, $S D=281.84)$ compared to a high-IEM leader $(M=-68.54, S D=315.57), t=0.47, p=.64, d=$ 0.09). However, participants were significantly less likely to invest in a company led by a male leader displaying low-IEM behaviors $(M=-156.25, S D=308.09)$ compared to a male leader displaying high-IEM behaviors $(M=-7.61, S D=281.65), t=2.44, p=.014$, Cohen's $d=0.50$. However, in terms of the female leadership trust advantage, there was no difference between high-IEM female leaders and high-IEM male leaders, $t=1.00, p=.31, d=0.20$, suggesting no advantage for female leaders under conditions of high uncertainty.

Effects on evaluative trust. We investigated whether individuals' evaluative trust in leaders depended on leader gender, leader behavior, and situational uncertainty. We conducted a 2 (Situational Uncertainty: low vs. high) x 2 (Leader IEM: low vs. high) x 2 (Leader Gender: male vs. female) between-subjects ANOVA on the mean evaluative trust score. Results showed a main effect of Leader IEM, $F(1,391)=33.94, p=.0001$, partial $\eta 2=.08$; participants trusted the leader more when the leader displayed high-IEM behaviors $(M=5.34, S D=0.92)$ compared to 
low-IEM behaviors $(M=4.72, S D=1.14)$ in response to a crisis. This finding supports Hypothesis 1.

When testing Hypothesis 3, the 3-way interaction for evaluative trust, $F(1,391)=2.91, p$ $=.089$, partial $\eta 2=.007$ was not significant, however the pattern of findings was in the predicted direction (see Figure 3). When the future of the company during the crisis was characterized by low uncertainty, participants trusted the female leader high in IEM more $(M=5.52, S D=0.78)$ than the male leader high in IEM $(M=5.06, S D=1.10), t=2.31, p=.02$, Cohen's $d=0.49$. However, similarly low levels of evaluative trust were observed for female leaders low in IEM $(M=4.73, S D=1.16)$ compared to male leaders low in IEM $(M=4.76, S D=1.20), t=0.14, p=$ .89 , Cohen's $d=0.02$. In terms of the within-gender comparisons, participants trusted female leaders high in IEM more than female leader low in IEM, $t=3.95, p=.0001$, Cohen's $d=0.79$. However, the analyses indicate no difference in trust for the male leader high (vs. low) in IEM, $t$ $=1.47, p=.14$, Cohen's $d=0.25$.

We also analyzed whether trust depended on gender and leader IEM under conditions of high uncertainty. In this case, IEM seemed to play a significant role for both male and female leaders. Participants trusted the female leader high in IEM more $(M=5.28, S D=0.96)$ than the female leader low in IEM $(M=4.72, S D=1.30), t=2.74, p=.006, d=0.49$. Similarly, participants trusted male leaders high in IEM $(M=5.45, S D=0.81)$ more than male leaders low in IEM $(M=4.67, S D=0.85), t=3.64, p<.001, d=0.94$. However, in terms of the female leadership trust advantage, there was no difference between high-IEM women and high-IEM men, $t=0.78, p=.43, d=0.19$, suggesting no leadership trust advantage for women under conditions of high uncertainty. Finally, an ANOVA with participant gender included as a fourth factor showed that participant gender did not further moderate this pattern of results, $F(1,382)=$ 
$0.26, p=.61$.

Mediation analyses. We also tested whether evaluative trust mediated the relation between our predictor variables and behavioral trust (investment), using the PROCESS macro (Hayes, 2013) for testing mediation and moderated mediation. We found that evaluative trust mediated the relationship between IEM and behavioral trust (investment). Moderated mediation analyses revealed that neither leader gender nor crisis uncertainty moderated this mediation, so we report simple mediation findings. Based on these findings, we suggest that higher IEM led to higher evaluative trust, $b=0.62, p<.0001$, which elicited higher investment in the target company, $b=57.43, p=.0001$. Moreover, the indirect effect from IEM to behavioral trust via evaluative trust was significant $b=35.37, S E=10.09,95 \% \mathrm{CI}[18.00,57.92]$. Higher evaluative trust accounted for the higher behavioral trust observed in the investment task.

\section{Discussion}

Using a similar paradigm but with a gender-neutral domain, in Study 2 we replicated and extended the finding of Study 1 that female leaders high in IEM benefit from a trust advantage by taking into consideration the nature of the crisis. Our results demonstrated that this advantage occurs only when the crisis is characterized by low uncertainty regarding the long-term consequences of the crisis; thus, highlighting the importance of relational skills in managing these types of crises. Extending our results from Study 1, we found these effects for both evaluative and behavioral measures of trust - the likelihood to invest in the company. We note that overall, as one would expect, the willingness to invest in a company in crisis was very lowmost scores were below 0 . The only condition under which there was more likelihood, on average, to invest in the company in crisis was when the leader was a woman high in IEM and the company was facing a low-uncertainty crisis. 
Finally, we note that although the overall interaction for evaluative trust is nonsignificant at .089 , the pattern of results is in the right direction. Not only are results consistent with the pattern of findings on evaluative trust in Study 1 and on behavioral trust in Study 2, but they are further strengthened by the results of a mediation test, showing that higher evaluative trust accounts for the higher behavioral trust observed in the investment task, suggesting the two outcomes are closely interrelated. Future research may explore alternative samples (larger or inperson) or adaptations of behavioral trust measures that may yield stronger overall effects.

\section{Additional Data and Analyses of Manipulations}

We collected additional data from 102 new Amazon Mechanical Turk participants to test possible alternative explanations for how participants may have perceived the IEM and uncertainty manipulations. Full sample, methods, and results descriptions are available in Supplementary File Section C at http... . To summarize, findings revealed that compared to low-IEM leaders, high-IEM leaders were perceived to be more relational and communal. Importantly, this pattern did not differ by leader gender, suggesting that participants did not interpret our IEM manipulation differently for female (vs. male) leaders. Ruling out alternative explanations, participants did not perceive high-IEM leaders to be more cautious than low-IEM leaders and also did not perceive high-uncertainty crises to be more severe than low-uncertainty crises, suggesting that our crisis severity does not confound our manipulation of crisis uncertainty.

\section{General Discussion}

We had several goals: to evaluate (1) whether or not leaders with high-IEM behaviors would elicit more evaluative and behavioral trust compared to those with low-IEM behaviors; (2) whether or not women (more than men) would elicit more evaluative and behavioral trust when 
they led with high-IEM behavior; and (3) whether or not the female leadership trust advantage for women who use high IEM would emerge when a firm faces a less (as opposed to more) uncertain crisis. We believe our findings yielded a number of important implications for the leadership and gender research.

Even though researchers have built up an impressive body of work on the likelihood of the preference for appointing women into top leadership positions following organizational crises (e.g., Ryan et al., 2016; Vongas \& Al Hajj, 2015), research on evaluations of incumbent leaders as crises unfold is rarer. This distinction is important because, while appointments reflect expectations of leadership potential, evaluations of incumbent leaders reflect reactions to their actual behaviors. Identifying what crisis management behaviors enhance trust in female leaders, and under what conditions such trust is enhanced, may, for example, help to mitigate the documented higher risk for women (compared to men) of being replaced during drawn-out crises (Cook \& Glass, 2013). Across our two organizational crisis studies, participants' relative trust in female (vs. male) leaders depended on perceptions of female leaders' relational behaviors and on the level of uncertainty about the consequences of the crisis. Our findings reinforce the importance of adopting a more nuanced attitude in theorizing potential organizational advantages (and disadvantages) to female leadership (e.g., Eagly, 2007; Eagly, 2016; Paustian-Underdahl et al., 2014; Post, 2015; Powell, Butterfield, \& Bartol, 2008; Vecchio, 2003).

We introduced a crisis-relevant relational behavior (IEM), arguing that, in an organizational crisis, it would contribute independently and in combination with leader gender to trustworthiness evaluations of, and trusting behaviors towards, leaders. As expected, participants in our organizational crisis studies exhibited more trust towards female leaders than towards male leaders, evaluating them as more trustworthy and behaving with more trust toward their 
organization, but only when these female leaders used high (vs. low) IEM and when the crisis consequences were more (vs. less) predictable. Our results provide a more precise picture of the presumed female leadership advantage during organizational crises. We suggest that to realize their leadership advantage potential, women may need to embrace relational leadership behaviors (Eagly et al., 2003), such as those conveyed by high IEM, at least under some circumstances. This finding may seem inconsistent with role congruity theory (Eagly \& Karau, 2002; GarciaRetamero \& Lopez-Zafra, 2006), which predicts that women in male-typed roles (e.g., senior leadership) will elicit negative evaluations for behaving in feminine ways. Perhaps the relational (female-typed) requirements that accompany organizational crises allow for more positive dispositions towards women who lead relationally. It is also possible that high-IEM behaviors may be preferred in non-crisis situations. Our results are consistent with research that finds women in senior executive roles have an advantage over men when they demonstrate relational capabilities (Rosette \& Tost, 2010). We corroborate prior evidence that relational behaviors elicit trust in a time of crisis (Jones \& George, 1998; Williams, 2007) and show that gender and IEM, combined with crisis characteristics, moderate the effect of IEM on participants' responses.

Because of the important role of context in perceptions and evaluations of leaders (e.g., Eagly, 2007; Eagly, 2016; Paustian-Underdahl et al., 2014; Post, 2015; Powell et al., 2008; Vecchio, 2003), we sought to establish boundary conditions for the emergence of a female leadership advantage among high-IEM leaders. We found that the female leadership advantage conferred on high-IEM women during organizational crises is conditioned upon the level of uncertainty about the crisis' consequences. Participants exhibited more trust towards female (vs. male) high-IEM leaders when the consequences of the crisis were foreseeable, but this advantage disappeared when the crisis consequences were unpredictable. This suggests that demonstrating 
superior relational skills (i.e., high IEM) may help women gain a leadership trust advantage in crises that primarily require relational skills (e.g., when the crisis consequences are predictable), but may not be as valuable in crises that require both agentic and relational leadership (e.g., when crisis outcomes are uncertain). In an organizational crisis, female (relative to male) leaders may generate more goodwill and resources for their organizations by using relational behaviors when the crisis fallout is predictable, but may not benefit from the same advantage in crises with uncertain consequences. Our finding that female leaders' high IEM brings trust advantages only in crises with more certain consequences, is consistent with the gender-in-context perspective of the female leadership advantage argument (Post, 2015; Rosette \& Tost, 2010). It is also consistent with a documented boundary condition to the "glass cliff" phenomenon: women are preferred over men for leading an under-performing firm when the low firm performance is attributed to a controllable cause, such as past leadership, but not when it is attributed to an uncontrollable cause, such as global economic circumstances (Kulich et al., 2015). However, Kulich and colleagues failed to include measures of leaders' behaviors or mechanisms through which leaders' behaviors might influence followers. We used relational behaviors (IEM) and a mechanism (trust) that, together, we suggest explain why female leaders may have an advantage in situations requiring relational skills.

In our effort to examine trust in the female leadership advantage argument, we evaluated not only others' evaluations of leaders' trustworthiness, but also behaviors that capture trust in the leader. We showed that participants' behavioral and evaluative reactions to female leaders under varying conditions of IEM and uncertainty were consistent. Participants' evaluations of leaders' trustworthiness and participants' investment behaviors towards leaders' firms showed similar patterns in responses to women and their IEM in two different crisis-uncertainty 
conditions. This suggests that leaders' relational leadership behaviors (i.e., IEM) affect not only people's feelings of trust and also their concrete actions, such as increased willingness to invest in the firm. Our findings are consistent with and reinforce research on trust in organizational crises, which shows how efforts to build or restore trust can influence such trusting behaviors as the provision of resources to the organization (Mishra, 1996).

\section{Theoretical Implications and Future Research Directions}

We extended the extant research on the female leadership advantage argument in five important ways. First, we theorized and empirically differentiated leader gender from gendered behaviors (IEM). Researchers who rely on leader gender as a proxy for relational skills confound gender and relational skills. We distinguished between the gender of the leader and behavioral manifestations of relationality (IEM). Some glass cliff studies have identified the separate effects of leader gender from those of leader gendered traits such as agency. For example, Kulich and her colleagues (2018) find that, when tasked with selecting a new CEO for a firm whose performance has been steadily declining, people chose leaders with an agentic personality profile over leaders with a communal personality profile independently of the leader's gender, because they perceived agentic leaders as being more task-oriented and, thus, more capable of implementing change. Ryan and colleagues' (2011) found that crises that were perceived as requiring people-management skills elicited more appointments of women; this suggests that relational skills expectations are an important factor in evaluations of female leaders in crises. Our finding, that gendered behaviors (IEM) explain significant variance in leadership trust (evaluations and behaviors), reinforces Fletcher's recommendation to identify, name, and reward "relational practices" (Fletcher, 1999) of leadership, which are otherwise often invisible in organizations. Given the importance of IEM in eliciting trusting attitudes and behaviors, 
researchers should identify additional relational practices in future research. For example, researchers may want to determine whether, and to what extent, the appointment of women to lead failing firms may also depend on their agentic versus (or in combination with) relational leadership behaviors.

Second, we extended the boundaries or context of leadership beyond the prototypical masculine contexts (Eagly, 2007; Eagly \& Carli, 2003; Eagly \& Karau, 2002). We examined uncertainty as a new boundary condition relevant to the female leadership advantage. The concept of uncertainty has a long tradition in organizational behavior (Duncan, 1972; Tversky \& Kahneman, 1974), yet researchers have not theorized its role in female leadership. Glass cliff studies, for example, focus on appointments to "risky and precarious" (Ryan et al., 2016, p. 446) leadership positions. However, risk is distinct from uncertainty, as very risky and precarious situations may entail a low level of uncertainty about possible outcomes. From a theoretical perspective, uncertainty introduces a new situational cue to the study of female leadership advantage, in that - at least in times of crisis - it may heighten perceptions of and expectations for relational skill requirements for leaders. Future studies may further develop understanding of how uncertainty affects evaluations of female and male leaders, and of relational leadership behaviors, for example by considering additional sources of uncertainty.

A third contribution we made to the female leadership advantage debate, is our inclusion of a new domain — trust — in which it may manifest. The majority of studies on the female leadership advantage have focused on evaluations of leaders' suitability for and effectiveness in leadership roles. Our research suggests that during organizational crises, a gendered leadership advantage manifests in evaluations of trustworthiness, and trusting behaviors towards leaders. We propose that trust may explain the documented link between female leadership and higher 
performance of organizations (Hoobler et al., 2018; Jeong \& Harrison, 2017; Post \& Byron, 2015). Examining the role of trust in explaining the poorly understood linkage between female leadership and organizational performance presents an avenue for future research. And future glass cliff studies may benefit from considering trust as a mediating mechanism for the relation between crisis characteristics and leader behaviors to explain the appointment of female (over male) leaders in failing organizations.

Fourth, by examining the gender leadership advantage argument in an unfolding organizational crisis context, we complement the literature on the glass cliff phenomenon - that is, "the tendency for women to be more likely than men to be appointed to leadership positions that are risky and precarious" (Ryan et al., 2016, p. 446). Evaluations of incumbent leaders reflect reactions to the performance of leaders during organizational crises, and our findings may help advance research on women's post-promotion leadership trajectories. For example, because successfully overcoming organizational crises requires financial and social support, the extent to which female leaders use relational behaviors (such as IEM) in managing crises may conditionvia trust — what resources and goodwill they may extract from their constituents. Our findings may also help to enhance our understanding of the "savior effect" phenomenon, which refers to female and minority leaders' higher rates of dismissal and of replacement by White male leaders when short-term firm performance declines (Cook \& Glass, 2013). Building on our findings about the importance, for female leaders, of behaving relationally in order to garner trust during controllable crises, researchers may want to account for the role of trust in understanding how leaders' display of relational behaviors, at times of declining firm performance, precipitate or temper their replacement by White male leaders.

Finally, we note that in the majority of studies about leadership and crises, researchers 
examine deteriorating financial performance as the focal crisis (Ryan et al., 2016). In our studies, we used a production crisis and a food product safety crisis as settings, which helps us to generalize the think-crisis, think-female phenomenon beyond the realm of crises in financial performance. Researchers, in the future, may find it enlightening to consider how various crisis characteristics moderate the relation between leadership and firm outcomes.

\section{Practice Implications}

The findings from our studies hold some important practical implications for human resource professionals and organizational leaders. Given the importance of IEM in eliciting trust, firms should consider hiring for, training, and rewarding IEM abilities in their leaders, especially in jobs with high potential for crises. IEM is an especially useful framework, as it points to specific categories of behaviors which can be learned, such as emotional response suppression, situation modification, cognitive change, and attentional deployment to the task. Further, based on our finding that expectations of IEM vary with uncertainty, female leaders may find it helpful to know that, when uncertainty around a crisis is low, using relational leadership behaviors may help them elicit more trust from others. The present study offers a useful conceptualization and test of the nature of this uncertainty. Leaders can use this framework to understand and address potential reactions from followers and the public when facing an organizational crisis.

\section{Limitations}

As any study, ours also has limitations. First, high- and low-IEM behaviors may be confounded with valence, such that high- (low-) IEM behaviors are primarily positive (negative). Yet, if our manipulation only captured valence, we would expect to find its effect independent of other variables - participants would trust more leaders with positive (vs. negative) behaviors. Instead, across all studies, we find interactions between IEM and other variables, in the direction 
predicted by our theorizing of relational behaviors and gender. Similarly, our high- (vs. low-) uncertainty conditions could be confounded by gendered interpretations. That is, in the highuncertainty condition a technical problem may refer to a masculine stereotype, while a human problem in the low-uncertainty condition could be potentially stereotyped as feminine. Although the results of both studies do not support this interpretation (i.e., male leaders were not consistently advantaged in high-uncertainty conditions), future studies need to address this issue by examining and manipulating contextual uncertainty using different study designs.

Second, although the majority of respondents had some work experience and were employed at the time of the study, the samples and setting we used present some limitations. Due to the nature of our experimental design, participants had limited information regarding the leader, organization, and industry they evaluated. However, maintaining tight experimental control necessitated this research design and allowed us to test the proposed interactions. Our setting mimics the general public's knowledge and evaluation of visible leaders and organizations. Nevertheless, future studies testing our hypotheses within real organizations and during actual organizational crises can provide further validity and reliability to our findings.

Third, in our study, men served as the comparison group, and we did not propose hypotheses regarding the conditions under which male leaders would accrue a trust advantage. However, consistent with our idea that low-uncertainty crises chiefly require relational skills, whereas high-uncertainty crises also require agentic skills, we predict that male leaders may benefit from a trust advantage when facing a high-uncertainty crisis and using high IEM (thus, showing both relational and agentic skills). This prediction warrants empirical assessment.

Finally, since in our Studies 1 and 2 we varied not only the uncertainty measure, but also the crisis setting (i.e., male-dominated versus gender-neutral domain; extent of public knowledge 
about the crisis), it could be possible that the statistically significant effect of uncertainty in Study 2 (compared to the non-statistically significant findings from Study 1) stemmed from crisis characteristics (rather than from the tightened uncertainty measure). Our post-hoc tests ruled out any concern that uncertainty may be measuring severity. Yet, we cannot fully exclude the possibility that the setting may amplify (or mute) the extent to which IEM confers more trustworthiness to high-IEM female (vs. male) leaders. Examining this possibility could be an interesting avenue for future research.

\section{Conclusions}

We explored how IEM and gender combine to influence trustworthiness evaluations of, and trust behaviors towards, incumbent female and male leaders and to what extent uncertainty exacerbates these gender-patterned relations. Our studies are some of the first to explore those factors together and we believe this research is relevant, given that organizations face crises and uncertainties on a regular basis. We call for more research on the presumed female leadership advantage and its nuanced manifestations, on the gendered nature of leadership behaviors during organizational crises, and on relational leadership qualities that help restore trust in organizations during uncertain times. We hope our research will encourage gender scholars, leadership scholars, and crisis management scholars to study the role of leaders' relational skills, such as emotion management. 


\section{References}

Anderson, K. J. (2014). Modern misogyny: Anti-feminism in a post-feminist era. Oxford: Oxford University Press. doi:10.1093/acprof:oso/9780199328178.001.0001

Belkin, L. Y., \& Rothman, N. B. (2017). Do I trust you? Depends on what you feel: Interpersonal effects of emotions on initial trust at zero-acquaintance. Negotiation and Conflict Management Research, 10, 3-27. doi:10.1111/ncmr.12088

Berg, J., Dickhaut, J., \& McCabe, K. (1995). Trust, reciprocity, and social history. Games and economic behavior, 10, 122-142. doi:10.1006/game.1995.1027

Berinsky, A. J., Huber, G. A., \& Lenz, G. S. (2012). Evaluating online labor markets for experimental research: Amazon. com's Mechanical Turk. Political analysis, 20, 351-368. doi:10.1093/pan/mpr057

Binns, J. (2008). The ethics of relational leading: Gender matters. Gender, Work \& Organization, 15, 600-620. doi:10.1111/j.1468-0432.2008.00418.x

Bordia, P., Hobman, E., Jones, E., Gallois, C., \& Callan, V. J. (2004). Uncertainty during organizational change: Types, consequences, and management strategies. Journal of Business and Psychology, 18, 507-532. doi:10.1023/B:JOBU.0000028449.99127.f7

Buhrmester, M., Kwang, T., \& Gosling, S. D. (2011). Amazon's Mechanical Turk a new source of inexpensive, yet high-quality, data? Perspectives on Psychological Science, 6, 3-5. doi: $10.1177 / 1745691610393980$

Buss, D. M. (1995). Psychological sex differences: Origins through sexual selection. American Psychologist, 50, 164-168. doi:10.1037//0003-066x.50.3.164

Casler, K., Bickel, L., \& Hackett, E. (2013). Separate but equal? A comparison of participants and data gathered via Amazon's MTurk, social media, and face-to-face behavioral 
testing. Computers in Human Behavior, 29, 2156-2160. doi:10.1016/j.chb.2013.05.009

Catalyst. (2019). Pyramid: Women in S\&P 500 companies. Retrieved from https://www.catalyst.org/knowledge/women-sp-500-companies

Chen, C. C., Saparito, P., \& Belkin, L. (2011). Responding to trust breaches: The domain specificity of trust and the role of affect. Journal of Trust Research, 1, 85-106. doi: $10.1080 / 21515581.2011 .552438$

Chopra, S., \& Sodhi, M. (2004). Managing risk to avoid supply-chain breakdown. MIT Sloan Management Review, 46, 53-62.

Clark, M. S., Oulette, R., Powell, M., \& Milberg, S. (1987). Recipient's mood, relationship type, and helping. Journal of Personality and Social Psychology, 53, 94-103. doi:10.1037//0022-3514.53.1.94

Cook, A., \& Glass, C. (2013). Glass cliffs and organizational saviors: Barriers to minority leadership in work organizations? Social Problems, 60, 168-187. doi:10.1525/sp.2013.60.2.168

Cook, A., \& Glass, C. (2014). Above the glass ceiling: When are women and racial/ethnic minorities promoted to CEO? Strategic Management Journal, 35, 1080-1089. doi:10.1002/smj.2161

Côté, S., \& Hideg, I. (2011). The ability to influence others via emotion displays: A new dimension of emotional intelligence. Organizational Psychology Review, 1, 53-71. doi:10.1177/2041386610379257

Cross, S. E., \& Madson, L. (1997). Models of the self: Self-construals and gender. Psychological Bulletin, 122, 5-37. doi:10.1037//0033-2909.122.1.5

Cunliffe, A. L., \& Eriksen, M. (2011). Relational leadership. Human Relations, 64, 1425-1499. 
doi:10.1177/0018726711418388

Duncan, R. B. (1972). Characteristics of organizational environments and perceived environmental uncertainty. Administrative Science Quarterly, 17, 313-327. doi: $10.2307 / 2392145$

Dutton, J. E., \& Dukerich, J. M. (2006). The relational foundation of research: An underappreciated dimension of interesting research. Academy of Management Journal, 49, 21-26. doi:10.5465/amj.2006.20785497

Eagly, A. H. (2007). Female leadership advantage and disadvantage: Resolving the contradictions. Psychology of Women Quarterly, 31, 1-12. doi:10.1111/j.1471$6402.2007 .00326 . x$

Eagly, A. H. (2016). When passionate advocates meet research on diversity, does the honest broker stand a chance? Journal of Social Issues, 72, 199-222. doi:10.1111/josi.12163

Eagly, A. H., \& Carli, L. L. (2003). The female leadership advantage: An evaluation of the evidence. The Leadership Quarterly, 14, 807-434. doi:10.1016/j.leaqua.2003.09.004

Eagly, A. H., Johannesen-Schmidt, M. C., \& van Engen, M. L. (2003). Transformational, transactional, and laissez-faire leadership styles: A meta-analysis comparing women and men. Psychological Bulletin, 129, 569-591. doi:10.1037/0033-2909.129.4.569

Eagly, A. H., \& Karau, S. J. (2002). Role congruity theory of prejudice toward female leaders. Psychological Review, 109, 573-598. doi:10.1037/0033-295x.109.3.573

Eagly, A. H., Karau, S. J., \& Makhijani, M. G. (1995). Gender and the effectiveness of leaders: A meta-analysis. Psychological Bulletin, 117, 125-145. doi:10.1037//00332909.117.1.125

Elsesser, K. M., \& Lever, J. (2011). Does gender bias against female leaders persist? 
Quantitative and qualitative data from a large-scale survey. Human Relations, 64, 15551578. doi:10.1177/0018726711424323

Feland, S. (2008). Janet Ang: Guiding transitions. Leadership in Focus. Retrieved from https://www.leadershipinfocus.net/

Fletcher, J. K. (1998). Relational practice: A feminist reconstruction of work. Journal of Management Inquiry, 7, 163-186. doi:10.1177/105649269872012

Fletcher, J. K. (1999). Disappearing acts: Gender, power, and relational practices at work. Cambridge, MA: The MIT Press. doi:10.1108/wimr.2000.15.5_6.303.1

Flynn, F. J., \& Staw, B. M. (2004). Lend me your wallets: The effect of charismatic leadership on external support for an organization. Strategic Management Journal, 25, 309-330. doi:10.1002/smj.377

Garcia-Retamero, R., \& Lopez-Zafra, E. (2006). Prejudice against women in male-congenial environments: Perceptions of gender role congruity in leadership. Sex Roles, 55, 51-61. doi:10.1007/s11199-006-9068-1

Glaeser, E. L., Laibson, D. I., Scheinkman, J. A., \& Soutter, C. L. (2000). Measuring trust. Quarterly Journal of Economics, 115, 811-846. doi:10.1162/003355300554926

Gloor, J. L., Morf, M., Paustian-Underdahl, S., \& Backes-Gellner, U. (in press). Fix the game, not the dame: Restoring equity in leadership evaluations. Journal of Business Ethics. doi:10.1007/s10551-018-3861-y

Gosling, S. D., Vazire, S., Srivastava, S., \& John, O. P. (2004). Should we trust web-based studies? A comparative analysis of six preconceptions about internet questionnaires. American Psychologist, 59, 93-104. doi:10.1037/0003-066x.59.2.93

Grant, A. M. (2007). Relational job design and the motivation to make a prosocial difference. 
Academy of Management Review, 32, 393-417. doi:10.5465/amr.2007.24351328

Grant, J. (1988). Women as managers: What can they offer to organizations. Organizational Dynamics, 16, 56-63. doi:.1016/0090-2616(88)90036-8

Gross, J. J., \& John, O. P. (2003). Individual differences in two emotion regulation processes: Implications for affect, relationships, and well-being. Journal of Personality and Social Psychology, 85, 348-362. doi:10.1037/0022-3514.85.2.348

Haddon, A., Loughlin, C., \& McNally, C. (2015). Leadership in a time of financial crisis: What do we want from our leaders? Leadership \& Organization Development Journal, 36, 612627. doi:10.1108/lodj-12-2013-0166

Haines, E. L., Deaux, K., \& Lofaro, N. (2016). The times they are a-changing... or are they not? A comparison of gender stereotypes, 1983-2014. Psychology of Women Quarterly, 40, 353-363. doi:10.1177/0361684316634081

Hayes, A. F. (2013). Introduction to mediation, moderation, and conditional process analysis: A regression-based approach. New York, NY: Guilford Press. doi:/10.1111/jedm.12050

Hendricks, K. B., \& Singhal, V. R. (2008). The effect of product introduction delays on operating performance. Management Science, 54, 878-892. doi:10.1287/mnsc.1070.0805

Holmes, J., \& Marra, M. (2004). Relational practice in the workplace: Women's talk or gendered discourse? Language in Society, 33, 377-398. doi:10.1017/s0047404504043039

Hoobler, J. M., Masterson, C. R., Nkomo, S. M., \& Michel, E. J. (2018). The business case for women leaders: Meta-analysis, research critique, and path forward. Journal of Management, 44, 2473-2499. doi:10.5703/1288284316077

Horton, J. J., Rand, D. G., \& Zeckhauser, R. J. (2011). The online laboratory: Conducting experiments in a real labor market. Experimental Economics, 14, 399-425. 
doi:10.1007/s10683-011-9273-9

Howard, E. S., Gardner, W. L., \& Thompson, L. (2007). The role of the self-concept and the social context in determining the behavior of power holders: Self-construal in intergroup versus dyadic dispute resolution negotiations. Journal of Personality and Social Psychology, 93, 614-631. doi:10.1037/0022-3514.93.4.614

Huang, L., \& Murnighan, J. K. (2010). What's in a name? Subliminally activating trusting behavior. Organizational Behavior and Human Decision Processes, 111, 62-70. doi:10.1016/j.obhdp.2009.10.002

Humphrey, R. H. (2002). The many faces of emotional leadership. The Leadership Quarterly, 13, 493-504. doi:10.1016/s1048-9843(02)00140-6

Hyde, J. S. (2005). The gender similarities hypothesis. American psychologist, 60, 581-592. doi:10.1037/0003-066X.60.6.581

Hyde, J. S., Bigler, R. S., Joel, D., Tate, C. C., \& van Anders, S. M. (2018). The future of sex and gender in psychology: Five challenges to the gender binary. American Psychologist. Advance online publication. doi:10.1037/amp0000307

Jeong, S.-H., \& Harrison, D. (2017). Glass breaking, strategy naking, and value creating: Metaanalytic outcomes of females as CEOs and TMT members. Academy of Management Journal, 60, 1219-1252. doi:10.5465/amj.2014.0716

Jolivet, E. (2013). Enquête sur les risques humains dans un departement R\&D de l'industrie aéronautique [An investigation of human risk in a $\mathrm{R} \& \mathrm{D}$ department within the aeronautics industry] (Unpublished master's thesis). University of Applied Sciences and Arts Western Switzerland, Geneva.

Jones, G. R., \& George, J. M. (1998). The experience and evolution of trust: Implications for 
cooperation and teamwork. Academy of Management Review, 23, 531-546. doi:10.5465/amr.1998.926625

Kahn, W. A., Barton, M. A., \& Fellows, S. (2013). Organizational crises and the disturbance of relational systems. Academy of Management Review, 38, 377-396. doi:10.5465/amr.2011.0363

Kirkman, B., Li, N., \& Porter, C. (2014). Toward a model of work team altruism. Academy of Management Review, 39, 541-565. doi:10.5465/amr.2011.0160

Kulich, C., Iacoviello, V., \& Lorenzi-Cioldi, F. (2018). Solving the crisis: When agency is the preferred leadership for implementing change. The Leadership Quarterly, 29, 295-308. doi:10.1016/j.leaqua.2017.05.003

Kulich, C., Lorenzi-Cioldi, F., Iacoviello, V., Faniko, K., \& Ryan, M. K. (2015). Signaling change during a crisis: Refining conditions for the glass cliff. Journal of Experimental Social Psychology, 61, 96-103. doi:10.1016/j.jesp.2015.07.002

Landers, R. N., \& Behrend, T. S. (2015). An inconvenient truth: Arbitrary distinctions between organizational, Mechanical Turk, and other convenience samples. Industrial and Organizational Psychology, 8, 142-164. doi:10.1017/iop.2015.13

Lawler, E. J. (2001). An affect theory of social exchange. American Journal of Sociology, 107, 321-352. doi: $10.1086 / 324071$

Lind, E. A. (2001). Fairness heuristic theory: Justice judgments as pivotal cognitions in organizational relations. In G. Greenberg \& R. Cropanzano (Eds.), Advances in organizational justice (pp. 56-88). Stanford, CA: Standford University Press.

Little, L. M., Gooty, J., \& Williams, M. (2016). The role of leader emotion management in leader-member exchange and follower outcomes. The Leadership Quarterly, 27, 85-97. 
doi:10.1016/j.leaqua.2015.08.007

Little, L. M., Kluemper, D., Nelson, D. L., \& Gooty, J. (2012). Development and validation of the Interpersonal Emotion Management scale. Journal of Occupational and Organizational Psychology, 85, 407-420. doi:10.1111/j.2044-8325.2011.02042.x

Mayer, J. D., Caruso, D. R., \& Salovey, P. (2000). Selecting a measure of emotional intelligence: The case for ability scales. In R. Bar-On \& J. D. A. Parker (Eds.), The handbook of emotional intelligence: Theory, development, assessment, and application at home, school, and in the workplace (pp. 320-342). San Francisco, CA: Jossey-Bass.

Mayer, R. C., \& Davis, J. H. (1999). The effect of the performance appraisal system on trust for management: A field quasi-experiment. Journal of Applied Psychology, 84, 123-136. doi:10.1037/0021-9010.84.1.123

Mayer, R. C., Davis, J. H., \& Schoorman, F. D. (1995). An integrative model of organizational trust. Academy of Management Review, 20, 709-734. doi:10.5465/amr.1995.9508080335

Milliken, F. J. (1987). Three types of perceived uncertainty about the environment: State, effect, and response uncertainty. Academy of Management Review, 12, 133-143. doi:10.5465/amr.1987.4306502

Mishra, A. K. (1996). Organizational responses to crisis: The centrality of trust. In R. M. Kramer \& T. R. Tyler (Eds.), Trust in Organizations: Frontiers of theory and research (pp. 261287). Thousand Oaks, CA: Sage. doi:10.4135/9781452243610.n13

Niven, K., Holman, D., \& Totterdell, P. (2012). How to win friendship and trust by influencing people's feelings: An investigation of interpersonal affect regulation and the quality of relationships. Human Relations, 65, 777-805. doi:10.1177/0018726712439909

Niven, K., Totterdell, P., \& Holman, D. (2009). A classification of controlled interpersonal affect 
regulation strategies. Emotion, 9, 498-509. doi:10.1037/a0015962

Paustian-Underdahl, S. C., Walker, L. S., \& Woehr, D. J. (2014). Gender and perceptions of leadership effectiveness: A meta-analysis of contextual moderators. Journal of Applied Psychology, 99, 1129-1145. doi:10.1037/a0036751

Pearson, C. M., \& Clair, J. A. (1998). Reframing crisis management. Academy of Management Review, 23, 59-76. doi:10.5465/amr.1998.192960

Post, C. (2015). When is female leadership an advantage? Coordination requirements, team cohesion, and team interaction norms. Journal of Organizational Behavior, 36, 11531175. doi:10.1002/job.2031

Post, C., \& Byron, K. (2015). Women on boards and firm financial performance: A metaanalysis. Academy of Management Journal, 58, 1546-1571. doi:10.5465/amj.2013.0319

Powell, G. N., Butterfield, D. A., \& Bartol, K. M. (2008). Leader evaluations: A new female advantage? Gender in Management: An International Journal, 23, 156-174. doi:10.1108/17542410810866926

Rosener, J. B. (1990). Ways women lead. Harvard Business Review, 68, 119-125.

Rosette, A. S., \& Tost, L. P. (2010). Agentic women and communal leadership: How role prescriptions confer advantage to top women leaders. Journal of Applied Psychology, 95, 221-235. doi:10.1037/a0018204

Rudman, L. A., \& Glick, P. (1999). Feminized management and backlash toward agentic women: The hidden costs to women of a kinder, gentler image of middle managers. Journal of Personality and Social Psychology, 77, 1004-1010. doi:10.1037//00223514.77.5.1004

Rudman, L. A., \& Glick, P. (2001). Prescriptive gender stereotypes and backlash toward agentic 
women. Journal of Social Issues, 57, 743-762. doi:10.1111/0022-4537.00239

Rudman, L. A., \& Glick, P. (2012). The social psychology of gender: How power and intimacy shape gender relations. New York, NY: Guilford Press.

Ryan, M. K., Haslam, S. A., Hersby, M. D., \& Bongiorno, R. (2011). Think crisis-think female: The glass cliff and contextual variation in the think manager-think male stereotype. Journal of Applied Psychology, 96, 470-484. doi:10.1037/a0022133

Ryan, M. K., Haslam, S. A., Morgenroth, T., Rink, F., Stoker, J., \& Peters, K. (2016). Getting on top of the glass cliff: Reviewing a decade of evidence, explanations, and impact. The Leadership Quarterly, 27, 446-455. doi:10.1016/j.leaqua.2015.10.008

Salovey, P., \& Mayer, J. D. (1989). Emotional intelligence. Imagination, Cognition and Personality, 9, 185-211. doi:10.2190/dugg-p24e-52wk-6cdg

Slatter, S., Lovett, D., \& Barlow, L. (2011). Leading corporate turnaround: How leaders fix troubled companies. San Francisco, CA: John Wiley \& Sons, Ltd.

Szulanski, G., Cappetta, R., \& Jensen, R. J. (2004). When and how trustworthiness matters: Knowledge transfer and the moderating effect of causal ambiguity. Organization Science, 15, 600-613. doi:10.1287/orsc.1040.0096

Thiel, C., Griffith, J., \& Connelly, S. (2015). Leader-follower interpersonal emotion management: Managing stress by person-focused and emotion-focused emotion management. Journal of Leadership \& Organizational Studies, 22, 5-20. doi: $10.1177 / 1548051813515754$

Tooby, J., \& Cosmides, L. (1990). The past explains the present: Emotional adaptations and the structure of ancestral environments. Ethology and Sociobiology, 11, 375-424. doi:10.1016/0162-3095(90)90017-z 
Trivers, R. (1972). Parental investment and sexual selection. In B. Campbell (Ed.), Sexual selection and the descent of man: 1871-1971 (pp. 136-179). Chigaco, IL: Aldine. doi:10.4324/9781315129266-7

Tversky, A., \& Kahneman, D. (1974). Judgments under uncertainty: Heuristics and biases. Science, 185, 1124-1131. doi:10.1126/science.185.4157.1124

Vecchio, R. P. (2003). In search of gender advantage. Leadership Quarterly, 14, 835-850. doi:10.1016/j.leaqua.2003.09.005

Vongas, J. G., \& Al Hajj, R. (2015). The evolution of empathy and women's precarious leadership appointments. Frontiers in psychology, 6, 1751. doi:10.3389/fpsyg.2015.01751

Weick, K. E. (1988). Enacted sensemaking in crisis situations. Journal of Management Studies, 25, 305-317. doi:10.1111/j.1467-6486.1988.tb00039.x

Weick, K. E. (1993). The collapse of sensemaking in organizations: The Mann Gulch disaster. Administrative Science Quarterly, 38, 628-652. doi:10.2307/2393339

Weick, K. E., \& Sutcliffe, K. M. (2001). Managing the unexpected: Assuring high performance in an age of complexity. San Francisco, CA: Jossey Bass.

Williams, H. M., Parker, S. K., \& Turner, N. (2007). Perceived dissimilarity and perspective taking within work teams. Group \& Organization Management, 32, 569-597. doi:10.1177/1059601106293769

Williams, M. (2007). Building genuine trust through interpersonal emotion management: A threat regulation model of trust and collaboration across boundaries. Academy of Management Review, 32, 595-621. doi:10.5465/amr.2007.24351867

Wood, W., \& Eagly, A. H. (2002). A cross-cultural analysis of the behavior of women and men: 
Implications for the origins of sex differences. Psychological Bulletin, 128, 699-727. doi:10.1037//0033-2909.128.5.699

Wooten, L. P., \& James, E. H. (2008). Linking crisis management and leadership competencies: The role of human resource development. Advances in Developing Human Resources, 10, 352-379. doi: $10.1177 / 1523422308316450$ 


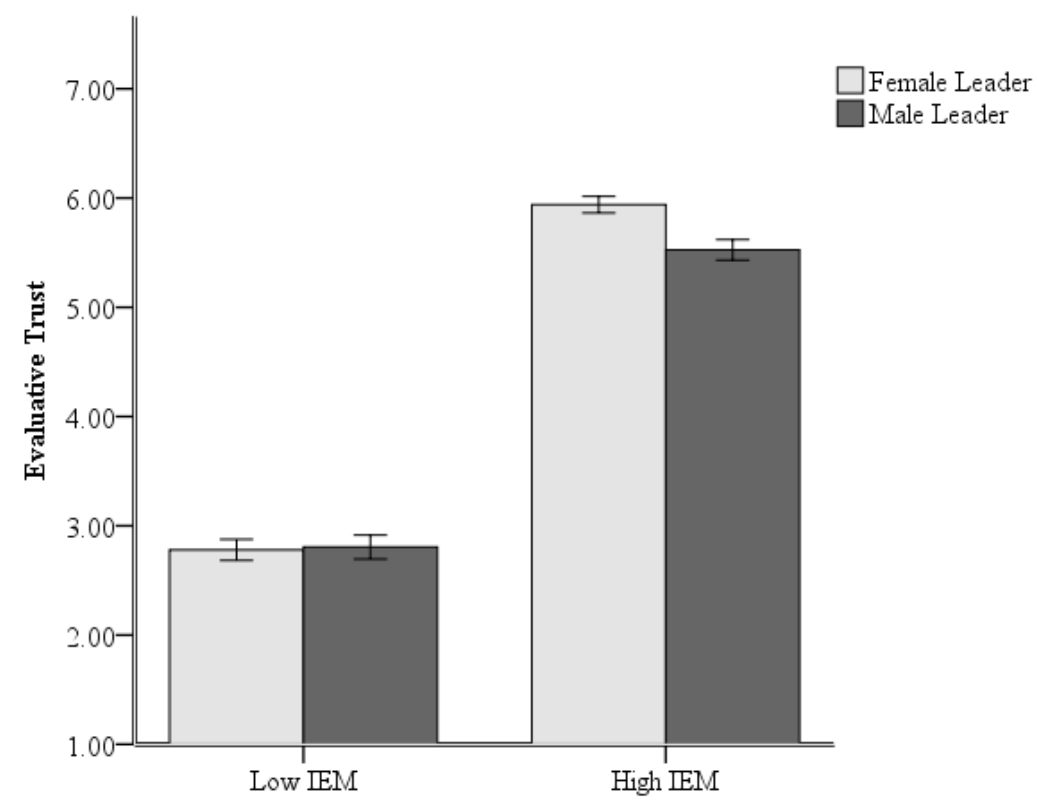

Figure 1. The interactive effects of interpersonal emotion management (IEM) and leader gender on evaluative trust in Study 1. Error bars represent standard errors. 

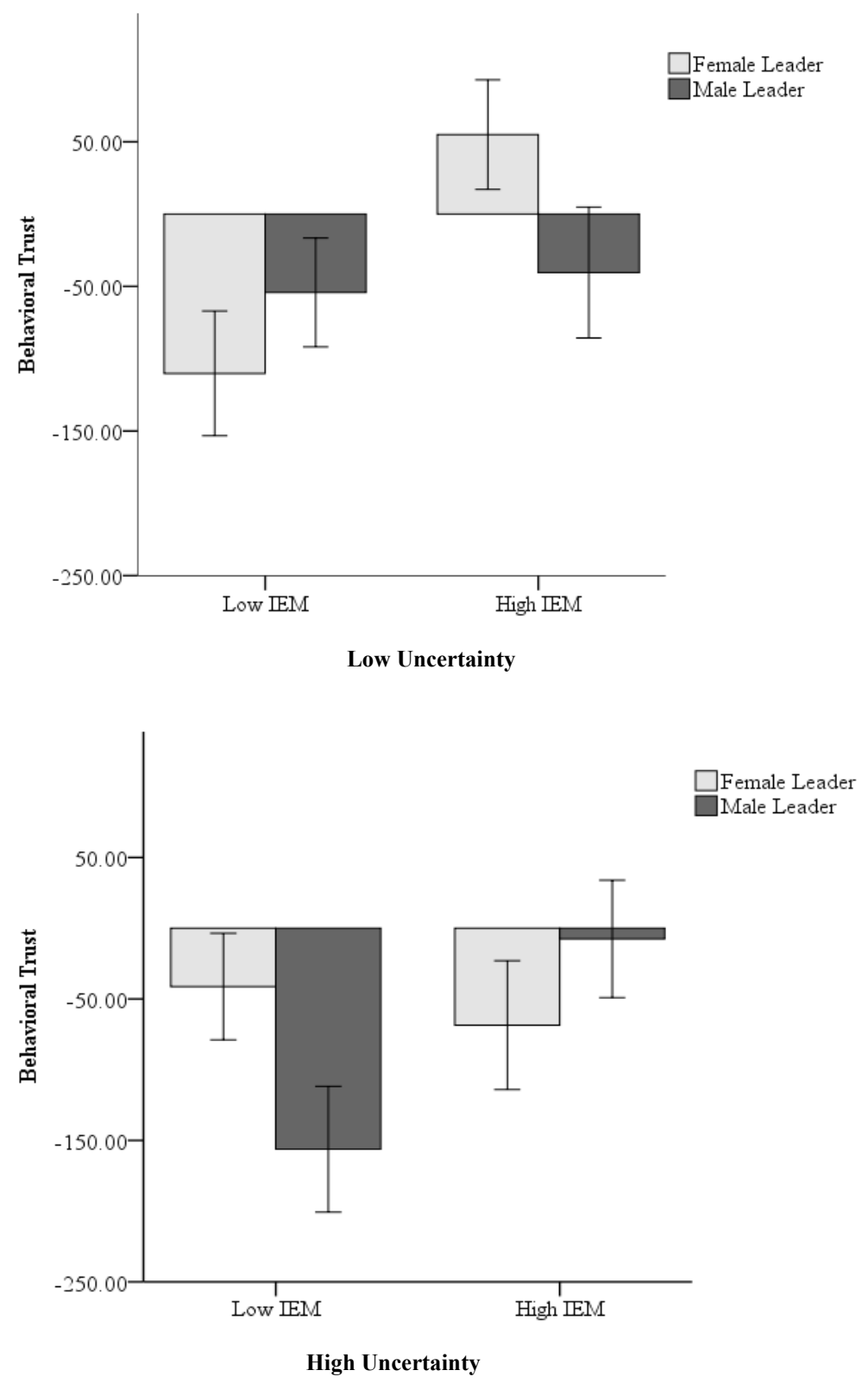

Figure 2. The interactive effects of interpersonal emotion management (IEM) and leader gender on behavioral trust in Study 2. Higher panel displays the interaction for low-uncertainty crises, lower panel for high-uncertainty crises. The behavioral trust outcome is a difference score between investment in QuickMex (target company) and another company. Higher positive numbers suggest more likelihood of investing in QuickMEX and a score of zero suggests equal investment in both companies. Error bars represent standard errors. 

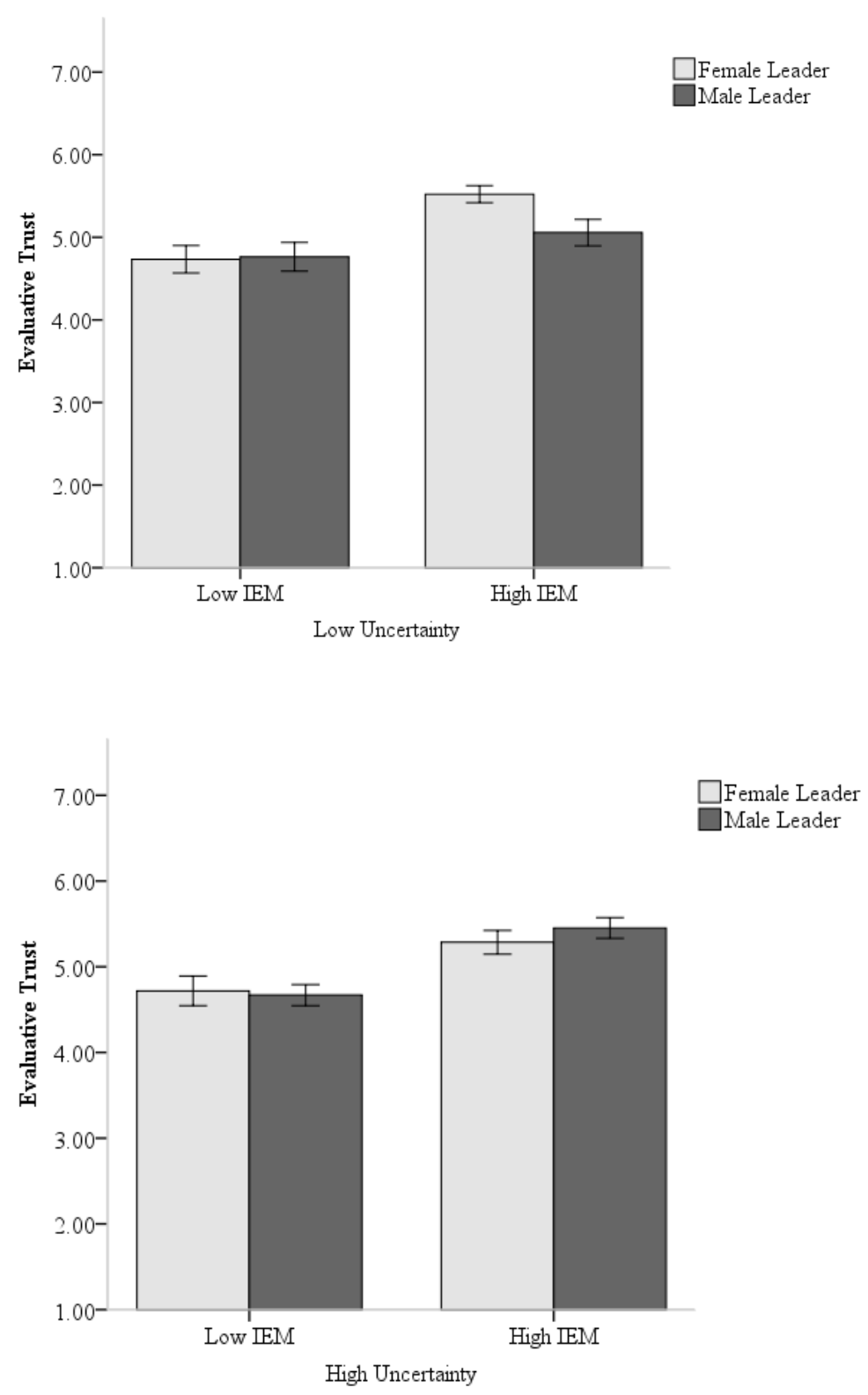

Figure 3. The interactive effects of interpersonal emotion management (IEM) and leader gender on evaluative trust in Study 2. Higher panel displays the interaction for low-uncertainty crises, lower panel for high-uncertainty crises. Higher scores suggest more trust in leader. Error bars represent standard errors. 